\title{
ZARRILLI COM AÇAÍ: TREINAMENTO PSICOFÍSICO COM ARTES MARCIAIS E MEDITATIVAS ASIÁTICAS NUM PEDACINHO DO NORTE DO BRASIL
}

\author{
Edson Fernando Silva \\ Mestre em Artes pelo Programa de Pós-Graduação em Artes do Instituto de Ciências da Arte da \\ Universidade Federal do Pará. Doutorando do Programa DINTER UFPA/UFMG \\ edson.arte@yahoo.com.br
}

Resumo

Este artigo tem como matriz de investigação o treinamento psicofísico com artes marciais e meditativas, sistematizado por Phillip B. Zarrili. A abordagem proposta se desenvolve por meio de "escrita criativa", procedimento metodológico apregoado e defendido por Sylvie Fortin, voltado ao desenvolvimento de narrativas que recorrem ao uso imbricado entre teoria e ficção para analisar dados coletados de uma pesquisa. Desse modo, a narrativa contextualiza a trajetória de Zarrili na tradição do treinamento psicofísico para atuantes do ocidente, reconstituindo ficcionalmente o percurso que vai desde os tempos de sua prática esportiva na universidade, sua iniciação ao mundo das artes marciais e meditativas em Kerela, na Índia, até sua adesão ao programa de treinamento psicofísico, desenvolvido por Adolf Clarence Scott, na Universidade de Wisconsin-Madison. Em seguida, a narrativa prossegue apresentando Cesário Augusto Pimentel como o discípulo de Zarrilli que garante a chegada deste legado ao norte do Brasil por meio da fundação do GITA - Grupo de Investigação do Treinamento Psicofísico do Atuante, ocorrida no ano de 2008, na cidade de Belém do Pará. A abordagem intercultural é assegurada pelo olhar nortista de quem narra os fatos.

Palavras-chave

Interculturalismo. Ficção. Teoria. Treinamento.
Abstract

This article has as matrix research the psychophysical training with martial and meditative arts, systematized by Phillip B. Zarrili. The proposed approach is developed through "creative writing", a methodological procedure proclaimed and defended by Sylvie Fortin focused on the development of narratives that resort to imbricated use of theory and fiction to analyze data collected from a research. Thus, the narrative contextualizes the Zarrili trajectory in the psychophysical training tradition in the West, retracing fictionally the route that goes from is time in his sports practice at the university, his initiation in the world of martial and meditative arts in Kerela, India, until his access to the psychophysical training program developed by Adolf Clarence Scott at Wisconsin-Madison University. Then, the narrative continues presenting Cesario Augusto Pimentel as the disciple of Zarrilli to ensure the arrival of this legacy to the north of Brazil through the foundation of the GITA - Group of Research in Psychophysical Training of Acting, which occurred in 2008, in the city of Belém do Pará. The intercultural approach is ensured by the northerner look who narrates the facts.

Keywords

Interculturalism. Fiction. Theory. Training. 
Zarrilli, ancestralidade e o açaí

Se você já experimentou uma boa tigela de açaí com granola ou banana, certamente não irá estranhar a combinação gastronômica proposta nas receitas a seguir: Adicione à tigela com açaí três ou quatro colheres de zarrilli em flocos, misture bem até os flocos se dissolverem, coloque açúcar a gosto e finalize com chantilly. Caso tenha um paladar mais exigente e clássico, o recomendável é utilizar a receita tradicional de açaí com granola e/ou rodelas de banana adicionando, somente ao final, zarrilli em grãos torrados e moídos. E para quem possui um paladar mais ousado e se permite experimentações gastronômicas exóticas, recomendo flambar três fatias finas de zarrilli no vinho do Porto - ao estilo carpaccio - e servi-las no molho al pesto como guarnição de acompanhamento à tigela de açaí. Verifique o que se afina com seu paladar, escolha uma das opções e bom apetite.

Identificou algo estranho nas receitas? Se o enigmático ingrediente 'zarrilli', apresentado em três modos diferentes de servir - em flocos, grãos torrados e moídos e em carne -, é a causa do estranhamento, então, certamente seu paladar já naturalizou o modo como o açaí é servido na região sudeste do Brasil, ou seja, uma espécie de suco de consistência cremosa, servido com granolas e/ou rodelas de banana.

“- Peraiiií: açaí com banana?!!". Certamente, essa seria a reação de minha falecida avó, incrédula e indignada diante de tamanha afronta

10 açaí é uma fruta roxa que nasce em cachos fartos de uma palmeira conhecida como açaizeiro. É natural do norte do Brasil, com grande incidência no estado do Pará. A extração do fruto é feita durante o ano inteiro, embora seu período mais abundante se encontre entre os meses de julho a dezembro. com o fruto regional. Dona Maria Dudolina, vulgo dona Dudu, natural da ilha de Mosqueiro distrito municipal de Belém do Pará -, ensinou aos seus oito filhos alguns preceitos sagrados sobre a degustação do açaí: "1 - Açaí bom é do grosso; 2 - Açaí se toma com bastante farinha d'água "inchada" (adicione bastante farinha na tigela, mexa até se tornar uma mistura homogênea e deixe descansar na geladeira por cinco minutos, para a farinha tufar); 3 - Tomar água na mesma cuia que tomou o açaí para evitar azia; 4 - Aquele que misturar açaí com banana está fadado à morte; 5 - Jamais tomar suco de outra fruta no mesmo dia em que se toma o açaí, pois também é caso de morte; 6 - Quem mistura açaí com leite morre durinho".

Esses ensinamentos foram preservados por minha mãe - também natural da ilha de Mosqueiro - e chegaram ao meu conhecimento por transmissão oral. Quando crianças, eu e meus dois irmãos nunca nos atrevemos a contrariar nenhum deles e a única concessão, permitida por minha mãe, era a adição de um pouco de açúcar para agradar nosso paladar infantil, propenso aos sabores adocicados.

Mas se, na minha tenra infância, o açaí era somente o alimento básico da população mais carente do estado do Pará e ainda pouco conhecido na região Sudeste do Brasil, hoje ele se tornou um produto de exportação nacional ${ }^{2}$ e internacional. Ao atravessar as fronteiras da

\footnotetext{
2 Segundo dados do SEBRAE, o açaí foi introduzido no mercado nacional gradativamente durante os anos oitenta do século passado. A pressão internacional pela preservação da floresta amazônica, ocorrida a partir da década de 1990, alavancou o consumo e a exportação do açaí, pois ele se tornou uma excelente alternativa de produto florestal não madeireiro, visto que a extração somente do fruto preserva a palmeira, diferentemente do processo de extração do palmito. O Pará é o maior produtor de açaí e estima-se que somente na capital Belém existam cerca de três mil pontos de vendas. Disponível em http://www.sebraemercados.com.br/a-importancia-do-acai-no-norte-do-brasil-e-o-vies-sustentavel-de-sua-producao/. Acessado em 18/08/2016.
} 
região norte e aportar, principalmente, no estado do Rio de Janeiro, outros hábitos gastronômicos foram introduzidos na sua degustação e, curiosamente, hábitos que vão de encontro a toda a sabedoria popular presente nos ensinamentos de minha avó.

Como eu seria capaz, então, de explicar à dona Dudu que o açaí passou a ser consumido em outras terras, tornando-se mania entre os adeptos do mundo fitness que agora o reverenciam como ícone maior de fonte de energia, considerando-o como alimento fundamental antes de uma boa sessão de malhação nas academias, pois quando tomávamos nossa boa e velha cuia de açaí com farinha d'água "inchada" - durante ou após o prato principal do almoço - tudo que nos restava após o seu consumo era um generoso cochilo - também conhecido como sesta -, deitados com a barriga pesada e tufada para cima, ao som do roncar dos atadores de rede de dormir que se espalhavam pelo pátio lateral da casa?

Se servir de consolo para minha querida avó, os especialistas em nutrição atestam que a fruta, embora possua alto teor energético, é recomendável como repositor de energias sendo indicado o consumo, portanto, para depois da prática de exercícios físicos e não antes, como costumavam propalar os "marombados" frequentadores de academia, por ocasião do boom inicial da fruta em terras estrangeiras ao Pará.

Mas, e açaí com zarrilli? Será que vó Dudu degustaria a versão em flocos, grãos torrados e moídos ou as deliciosas fatias flambadas ao vinho do Porto? A questão, talvez, seja bem mais fácil de responder e menos complexa do que os desdobramentos interculturais envolvendo a degustação do açaí nos estados do sudeste do Brasil. E a razão é simples: "zar- rilli", grafado desse modo, iniciando com letra minúscula, não é um ingrediente e jamais será encontrando em nenhuma das três versões supracitadas.

Por essa informação a vó Dudu não esperava e certamente ficaria aliviada com a descoberta. "- O bom e velho açaí com farinha inchada de Mosqueiro está assegurado!", exclamaria ela, entre suspiros efusivos de alegria. Recomposta do susto, restar-lhe-ia a dúvida: "Ora bolas, mas que diacho é esse negócio de zarrilli?". "Calma vó." - O certo seria perguntar não 'o quê', mas sim 'quem' é Zarrilli. - "Isso só pode ser atentação ${ }^{3}$ de menino!", retrucaria com um sorriso entreaberto na boca. E ela estaria correta nesta constatação, pois o 'zarrilli' retratado até agora é apenas uma licença poética que me permite inaugurar o debate acerca das trocas, compartilhamentos e apropriações culturais entre pessoas de lugares bem distantes: Phillip B. Zarrilli e seu estúdio particular (Tyn-y-parc C.V.N. Kalari/Studio), localizado no País de Gales, e o meu próprio trabalho de pesquisa no GITA - Grupo de Investigação do Treinamento Psicofísico do Atuante, de Belém do Pará, norte do Brasil. Terras distantes, culturas diferentes que se encontram atadas pelo legado da tradição do treinamento psicofísico com artes marciais e meditativas asiáticas, sistematizado e transmitido pelo mestre, Zarrilli, para o pequeno círculo de discípulos que se formou na distante cidade das mangueiras.

\section{Procurando o mestre} entre os mestres

Movido pela curiosidade criativa e pelo espírito científico, realizei uma consulta informal

3 Molecagem, peraltice, brincadeira de criança atentada. 
entre estudantes e professores de teatro, atores, atrizes e diretores que produzem teatro em Belém do Pará, a pretexto de discutir o tema "Alimentação e condicionamento físico para artistas de teatro". A metodologia aplicada consistia em aplicação de entrevista semiestruturada com três perguntas simples e diretas: 1 - Seu condicionamento físico para a cena está diretamente ligado à sua alimentação?; 2 - Em dia de apresentação, você realiza alguma restrição alimentar para melhorar o condicionamento físico?; 3 - Você se arriscaria a tomar 'açaí com zarrilli' no dia de uma apresentação? Obviamente, introduzi a licença poética com o nome de Zarrilli intencional e capciosamente para verificar se o trabalho internacionalmente reconhecido deste autor seria evocado por este público seleto da consulta. O resultado foi o seguinte: $35 \%$ dos entrevistados foram diretos e disseram que sob hipótese nenhuma tomariam açaí no dia de uma apresentação, independente do acompanhamento, por se tratar de um alimento que pesa na barriga do paraense; $60 \%$ não conheciam o ingrediente e ficaram curiosos para saber o que era 'zarrilli'; $5 \%$ sabiam que 'zarrilli' não era ingrediente e sim um autor estrangeiro, embora não soubessem maiores informações sobre ele.

Do universo de $60 \%$ dos curiosos sobre o ingrediente, inventei a seguinte explicação: 'zarrilli' é uma espécie de farinha de tapioca alterada em laboratório em pesquisas recentes, realizadas por estudantes de bioquímica da UFPA, em parceria com a agroindústria japonesa. A vantagem desta sobre a tradicional farinha de tapioca seria a aceleração do processo digestivo do açaí, eliminando, portanto, boa parte da sensação de peso que o alimento deixa depois de consumido. Após apresentar esta versão, o resultado foi o seguinte: $40 \%$ se mostraram interessados em experimentar a tal farinha e não questionaram a explicação; 35\% se convenceram da explicação, mas se mostraram céticos com os efeitos do ingrediente; $25 \%$ se mostraram incrédulos com a explicação e questionaram sobre o que de fato seria 'zarrilli'.

No encerramento da consulta, eu perguntava - para o universo dos $100 \%$ dos entrevistados - sobre a pesquisa de treinamento psicofísico com artes marciais e meditativas asiáticas, desenvolvida por Phillip B. Zarrilli, ocasião em que deixava claro que a intenção da consulta era averiguar o nível de penetração do trabalho do autor na cidade. É curioso - mas não surpreendente - observar, neste momento, que o nome de outros autores imediatamente eram evocados pelos entrevistados, como reconhecimento de uma área temática específica voltada ao treinamento de atores: Constantin Stanislavski, Jerzy Grotowski, Eugênio Barba e Peter Brook invariavelmente são citados. Digo não me surpreender, pois estamos falando de autores considerados reformadores do teatro do século $X X$ - os dois últimos em plena atividade até hoje - cujo pensamento e obra exercem grande influência no mundo inteiro.

E não é muito difícil explicar o fato de Zarrilli não ser reconhecido pelos entrevistados entre estes mestres do teatro: sua extensa produção bibliográfica, que inclui nada menos do que a participação em nove livros ${ }^{4}$ - dos quais quatro

\footnotetext{
4 Como autor: The Kathakali Complex: Actor, Performance, Structure (1984); When the Body Becomes All Eyes: Paradigms, Pratices, and Discourses of Power in Kalarippayattu, a South Indian Martial Art (1998), Kathakali Dance-Drama: Where Gods and Demons Come to Play (2000), Psychophysical Acting: an intercultural approach after Stanislavski (2008). Como Co-autor: Theatre Histories: An Introduction (2006), Acting: Psychophysical Phenomenen and Process (2013). Como editor: Indian Theatre: Traditions of Performance (1990), Asian Martial Arts in Actor Training (1993), Acting Reconsidered: Theories and Pratices guide (2002).
} 
como autor, dois como co-autor e três como editor - e mais de vinte ensaios refletindo sobre treinamento psicofísico e atuação, não se encontra publicada em língua portuguesa e raros são os trabalhos publicados no Brasil que mencionam o nome do diretor, performer e pedagogo Phillip B. Zarrilli. Situação diversa dos autores mencionados acima que, se ainda não foram completamente traduzidos, possuem ao menos suas obras seminais traduzidas e publicadas em língua portuguesa. Em decorrência disso, é possível afirmar que a formação de atores e atrizes em Belém do Pará, no que toca especificamente ao treinamento para atuação, vincula-se diretamente ao legado desses autores supracitados e neles encontra a terminologia, noções e conceitos que orientam uma poética criativa muito presente na cidade.

Zarrilli: o caminho do mestre ${ }^{5}$

O ano é 1976 e eu apenas ensaiava movimentos singelos de espreguiçamento fetal no confortável útero de minha mãe. Mas o jovem Phillip Zarrilli já rumava, pela primeira vez, ao estado de Kerela, sul da Índia, para sua jornada ao encontro das artes marciais e meditativas asiáticas. Imagino a cena: um jovem americano, aparentando aproximadamente trinta anos de idade, fisicamente forte e saudável, de mochila nas costas e um sorriso meio amarelo no rosto, entrando pela primeira vez no kalari de Gurukkal Govindankutty Nayar. A cena talvez não fosse de surpreender aquele que vi-

5 A narrativa ficcional elaborada neste tópico tomou como fonte o relato do próprio Zarrili contido no capítulo 15 da segunda edição da obra Acting (re)considered: a theoretical and practical guide (2002). ria a ser o mestre de kalarippayttu de Zarrilli, posto que a visita de ocidentais para conhecer aquela arte milenar havia se tornado um tanto rotineira naqueles anos da década de 70 do século passado. Mas certamente o Gurukkal Govindankutty Nayar não suspeitava, naquele exato momento, que aquele jovem se tornaria o seu discípulo mais ilustre, vindo a ser o primeiro ocidental a obter autorização para ensinar kalarippayattu e abrir um kalari no ocidente - Tyn-y-parc C.V.N. Kalari/Studio, localizado no País de Gales.

A caminhada, àquela altura, no entanto, só estava começando para o jovem cheio de inquietações, dúvidas e conflitos provenientes principalmente das práticas esportivas que até então havia se dedicado: beisebol, wrestling, basquete, futebol e futebol americano. Tendo uma vida universitária semelhante a de seus colegas, dedicou-se a todas estas práticas que, invariavelmente, estavam voltadas para o culto do corpo saudável, forte e competitivo. Esta experiência esportiva certamente lhe proporcionou fortalecimento, condicionamento físico, disciplina e autoconfiança, sendo estes dois últimos princípios importantes a serem cultivados para além dos campos e quadras esportivas. O problema é que, paralelamente a isso, Zarrilli também cultivava os ideais e princípios éticos de uma filosofia pacifista que gradativamente se consolidava em seu íntimo. E o futebol americano, sobretudo, o incitava a um estado de agressividade, explosão de energia e força bruta, próprio deste esporte de contato. Imagine um pacifista ouvindo, aos berros, as seguintes orientações do técnico: "Vamos Zarrilli, que moleza! Empurra, esmaga, arrebenta com eles. Levanta seu burro e mete a porrada neles!" Crescia a sensação, então, de que aquelas práticas, sequestravam seu corpo 
e o direcionavam contra suas crenças e valores éticos. A cisão entre corpo e mente, própria do dualismo cartesiano, se cristalizava a duras penas no jovem desportista Zarrilli.

Quem aporta na Índia em 1976, portanto, é um jovem cheio de tensões e disposto a integrar sua mente e seu corpo por meio das artes marciais e meditativas. $O$ exotismo que envolve uma viagem ao oriente em busca de se reencontrar, logo deu lugar a dura rotina de sete horas diárias de exercícios voltados ao aprendizado da "dança-teatro" Kathakali, sob a orientação de M. P. Sankaran Namboodiri e mais quatro horas de treinamentos diários na arte marcial Kalarippayattu, sob orientação direta de Gurukkal Govindankutty Nayar no Kalari, Thiruvananthapuram. Assim foram os primeiros seis meses de intensa prática e observação direta junto aos mestres.

Embora Zarrilli fosse extremamente dedicado, a prática desportiva de outrora estava arraigada em seu corpo, o que dificultava a compreensão de como seus mestres - em particular o de Kalarippayattu - conseguiam desempenhar todas aquelas combinações acrobáticas de passos, chutes, saltos e giros com força, destreza e fluidez. Aos seus olhos, elas pareciam, ao mesmo tempo, duras como um diamante e leves como algodão. Seus movimentos fluiam com a mesma naturalidade com que a correnteza do rio é capaz de mover grandes rochas. Por um bom tempo, esforçou-se para imitar aquelas formas codificadas de dança e luta - Kathakali e Kalarippayattu, respectivamente - intentando atingir a mesma fluidez de seus mestres, mas, por um bom tempo, tudo que conseguiu foi reproduzir a forma externa e dura dos movimentos codificados.

O tempo e a paciência, talvez, tenham sido a primeira grande lição que o treinamento the reservou: aprender a forma, penetrar na forma, para, enfim, ultrapassá-la e tonar-se a própria forma. Não se trata do dualismo forma/conteúdo, mas sim forma e conteúdo integrados num todo orgânico e dinâmico. O bailado vigoroso dos mestres, assim, Ihe saltava aos olhos como demostração eficaz de fluidez, força, equilíbrio, precisão, energia e autocontrole. $\mathrm{E}$ foi isso que perseguiu durante anos de prática. O caminho apresentado pelos mestres não tinha mistério: repetir, repetir, repetir, repetir, repetir, repetir, repetir, repetir, repetir, repetir, repetir, repetir, repetir, repetir, repetir, repetir, repetir, repetir, repetir, repetir, repetir, repetir, repetir, repetir... Pela repetição do treinamento, conquistou um novo modo de lidar com sua mente e seu corpo foi se arraigando gradativamente e se, outrora, suas práticas esportivas Ihe impulsionavam para conquistar a qualquer custo um objetivo preciso - a vitória na competição - aos poucos passou a perceber e dominar um estado de prontidão e consciência dos movimentos, da respiração, do olhar, do espaço ao redor; aos poucos, deixou de repetir formas, penetrou as formas e tornou-se as formas, tal como seus mestres de Kathakali e Kalarippayattu; não mais observava o fluir do rio, tornou-se o proprio rio; usando uma expressão do dialeto malayali, Zarrilli estava se apropriando de um estado psicofísico em que "o corpo se torna todos os olhos" - meyyu kannakuka.

Foram sete anos intensos de dedicação sendo os doze primeiros meses também dedicados ao Kathakali - e várias viagens de retorno a Kerela para alcançar a compreensão e o domínio do Kalarippayattu, vindo a ser reconhecido com este grau de competência em 1988 por seu próprio mestre, Govindankutty Nayar. Mais tarde, no ano 2000, Zarrilli inaugu- 
ra, no País de Gales, o Tyn-y-parc CVN Kalari, considerado o primeiro kalari oficial localizado fora de Kerela e tendo o próprio Phillip como Gurukkal.

\section{Zarrilli e o programa}

\section{de treinamento de A. C. Scott}

Os dois primeiros anos de intensa pesquisa na Índia renderam uma tese de doutorado intitulada "Kalaripayattu e o atuante. Oriente e ocidente, Passado, Presente, Futuro"6, defendida em 1978, na Universidade de Minnesota, EUA. Em 1979, Zarrili começou uma extensa colaboração junto ao programa de treinamento psicofísico para atuantes, desenvolvido por Adolf Clarence Scott, na Universidade de Wisconsin-Madison. O programa, criado por Scott em 1963, estava voltado para atores-alunos de graduação daquela universidade americana e tinha como fundamento a prática diária do t'ai chi ch' uan (estilo Wu). Scoott perseguia o mesmo ideário do francês Jacques Copeau que, já nas primeiras décadas do século $X X$, buscava um processo de formação e treinamento que proporcionasse autonomia, autoconfiança, disciplina, prontidão, energia e criatividade - entre outros -, princípios que se colocavam para muito além de uma simples preparação física do atuante. Todos esses princípios se articulavam exatamente com o que Zarrilli acabara de vivenciar em Kerela, seja com o Kathakali ou com o Kalarippayattu. Logo, aderiu a esta nova arte marcial, vindo a treinar t'ai chi ch' uan diretamente com Scott.

As inúmeras viagens de retorno a Kerela durante sete anos - sempre motivado pelo

6 Título original: "Kalarippayatt and the perfoming artist. East and West, Past, Present, Future". processo de aprendizado e amadurecimento do Kalarippayattu - também lhe proporcionou uma imersão no treinamento de ioga, arte meditativa asiática que compõe a sistematização de treinamento para atuantes proposto por Zarrilli para se integrar ao programa de Scott.

A colaboração entre Zarrilli e Scott, gradativamente, constituiu uma abordagem intercultural alternativa voltada para a compreensão e prática cênica que objetiva despertar e aprimorar a percepção sinestésica do atuante no momento de sua atuação. Robert Benedetti (1973, p. 463), mesmo antes da participação de Zarrilli no programa, definiu como princípio fundamental deste treinamento alcançar e dominar uma espécie de "tranquilidade no centro"7, princípio elementar identificado na tradição do teatro oriental; o mesmo princípio que permite aos mestres de kalarippayattu se movimentarem com leveza, suavidade, força e vitalidade e que havia sido testemunhado por Zarrilli durante sua formação em Kerela. Embora estivessem executando sequências de movimentos codificados, incluindo expansivos saltos, chutes e giros, tudo era realizado com extrema delicadeza, como se mantivessem um estado de "tranquilidade no centro" mesmo estando em frenética dinâmica de movimentos. E este será o grande desafio para todos aqueles que passarão a se dedicar ao treinamento psicofísico com artes marciais (t'ai chi ch' uanekalarippayattu) e meditativas (hatha yoga): encontrar e dominar um estado de "tranquilidade no centro" que permita o fluir natural e orgânico de todas as ações realizadas em cena. Tal como um artista marcial que domina este estado de "tranquilidade no centro" para

7 Sobre este princípio ver o artigo intitulado "What We Need to Learn from the Asian Actor", de Benedetti, publicado em 1973 no Educational Theatre Journal. 
se manter sempre alerta e em estado de prontidão para qualquer necessidade no combate, o atuante deve dominá-lo para o seu processo de criação e atuação disciplinando sua energia, foco e atenção; disciplina, portanto, voltada para um trabalho em que mente e corpo encontram-se integrados e em equilíbrio.

\section{Cesário Augusto: o discípulo que herdou a tradição do mestre Zarrilli}

Há uma expressão popular em Belém que ficou famosa quando entoada pelo compositor Pinduca ${ }^{8}$ que diz o seguinte: "Quem vai ao Pará, parou. Tomou açaí ficou”. Cesário Augusto Pimentel de Alencar, natural da cidade do Rio de Janeiro, é um desses sujeitos que foi capturado pela barriga. Felizmente, quando aportou em terras paraenses, foi devidamente apresentado à fruta regional, sendo que na sua tigela de açaí só havia farinha d'água e um pouco de açúcar. Foi o suficiente para deixá-lo com a sensação de que, nesta cidade de calor intenso e povo hospitaleiro, o futuro lhe reservaria um pequeno solo sagrado para cultivar os ensinamentos de seu mestre Zarrilli.

Em janeiro de 2004, Cesário havia recém concluído seus estudos de doutorado em Práticas Performáticas, pela University of Exeter. Sua tese que viria a ser intitulada The shining self: the actor's journey from character to role problematizava a falta de definição e aplicação para os termos "personagem" e "papel", o que, via de regra, ocasiona confusão tanto na teoria quanto na prática nas montagens teatrais de processos criativos contemporâneos.

8 Aurino Quirino Gonçalves é natural de Igarapé-Miri, interior do estado do Pará. Cantor e compositor de várias canções de carimbó.
No entanto, como já conhecia a proposta metodológica de Zarrilli com o treinamento psicofísico por meio de artes marciais e meditativas, deslocou-se para o Reino Unido cheio de segundas intenções. Já em terras britânicas, na primeira oportunidade que teve, apresentou-se ao mestre e o inquiriu, assim, na bucha: "Posso participar do módulo de treinamento para graduandos e pós-graduandos?". Sem meias palavras, o mestre sentenciou: "Se não Ihe atrapalhar na tese de doutorado, seja bemvindo, Cesário". Era o começo do seu aprendizado no treinamento psicofísico que se estenderia paralelamente durante toda a elaboração de sua tese.

A identificação com metodologia proposta por Zarrilli foi imediata e, juntamente com outros colegas, montou um grupo fechado para treinamentos em tempo extra. Tamanha dedicação rendeu a participação em quatro montagens teatrais: The Kiss on the tarmac (a partir da dramaturgia de Nelson Rodrigues, "O beijo no asfalto"), The twelfth night ("Noite de Reis", de William Shakespeare) The non-existent Knight (a partir do romance de Ítalo Calvino, "O cavaleiro inexistente"). Atuou na função de diretor nas duas primeiras montagens e se auto-dirigiu na montagem em solo da última. Por fim, participou como atuante, ao lado da primeira turma que Zarrilli formou em Exeter, sendo dirigido pelo próprio mestre na montagem The Walter Station. Desse modo, quando chegou a Belém, em dezembro de 2003, para ministrar uma oficina intensiva intitulada "Um treinamento psicofísico para o interprete" promovida pelo Instituto de Artes do Paráa, Cesário trazia na bagagem a herança fresquinha de

9 Em 2015, o Governo do Estado do Pará, por conveniências políticas e econômicas, transformou todas as suas fundações e institutos em um único órgão denominado genericamente como Casa das Artes. 
todo seu aprendizado em Exeter.

Um murmurinho logo se espalhou na cidade, entre os atuantes de teatro, sobre aquele estranho cidadão vindo de uma recém formação na Europa, com domínio em artes marciais asiáticas. Logo se criou a expectativa e a imagem de uma espécie de guru oriental que nos iniciaria no fantástico mundo dos combates marciais. Imbuídos, assim, por uma espécie de espírito de Daniel Larusso ${ }^{10}$, aguardávamos pela chegada de nosso Sr. Miyagi, o mestre marcial que nos revelaria os segredos para um excelente "trabalho de corpo" no palco. A expressão "trabalho de corpo", aliás, merece um pequeno adendo para contextualizar e dimensionar a importância e expectativa gerada com a oficina que seria ministrada por Cesário.

Ainda recorrente nos dias atuais, a expressão "trabalho de corpo" é usada, em Belém, para identificar um domínio técnico, sobretudo físico, na arte da atuação. É comum as conversas pós apresentações se concentrarem em torno da verificação se os atuantes daquela montagem possuíam, ou não, um bom "trabalho de corpo". Os parâmetros utilizados para tal verificação, invariavelmente, são: quantidade de energia despendida, execução de movimentos acrobáticos como saltos, giros e rodopios, domínio e realização de alguma técnica específica, como tecido aéreo, pernade-pau e/ou trapézio, e ainda toda sorte de habilidades voltadas para o cultivo do domínio físico em cena. Desse modo, é o virtuosismo técnico (cf. BARBA, 2012, p.16) que prevalece e se estabeleceu instintivamente no imaginário dos atuantes da cidade. Diante desse contexto, pode-se imaginar a expectativa criada para

10 Personagem do clássico filme dos anos oitenta Karatê Kid - A hora da verdade (1984), interpretados respectivamente por Ralph Machino e Pat Morita. Direção de John G. Avildsen. participação em uma oficina com artes marciais asiáticas.

A primeira impressão foi animadora e satisfazia nossa expectativa hollywoodiana em torno do guru marcial: Cesário cultivava os cabelos longos - aproximadamente, um palmo abaixo dos ombros -, bigode e cavanhaque fartos e um porte físico atlético - musculatura das pernas e braços definidos, peitoral estufado e zero de barriga. Trajava camiseta regata branca e uma calça moletom cinza, bastante surrada, amarrada por um fio acima da altura do umbigo - quase próximo a altura do peito. Com voz suave e tom quase sussurrante, conduziu a oficina que contava com trinta entusiasmados atuantes da cidade que perseguiam aprimorar o "trabalho de corpo". A combinação de dois termos estranhos ao nosso vocabulário àquela altura, no entanto, logo nos instigaria a pensar para muito além do virtuosismo que nos levara até ali e nos faria reavaliar nossas expectativas: treinamento psicofísico. $O$ legado de Zarrilli, assim, aportava no norte do Brasil pela primeira vez.

Conduzindo tudo com sua fala mansa, Cesário aplicou o aprendizado prático envolvendo parte do treinamento psicofísico sistematizado por Zarrilli: 1 - apresentou a dinâmica de funcionamento prático do suryanamaskar, isto é, a sequência codificada de movimentos conhecida como "saudação ao sol" que envolve aproximadamente doze posturas diferentes do hatha yoga, todas trabalhadas controlando $\mathrm{e}$ mantendo atenção às três fases da respiração: puraka (inspiração), kumbhaka (retenção) e rechaka (expiração); 2 - um pequeno fragmento da sequência codificada de movimentos do t'ai chi ch' uan, estilo wu, ressaltando sempre o processo de percepção, conexão e domínio do centro vital de energia, localizado três dedos 
abaixo do umbigo em sintonia com a respiração mais fluida; 3 - a mesma orientação com o centro vital de energia na realização das posturas abstraídas de animais (elefante, leão, cavalo e serpente) praticadas no kalarippayattu.

Repetir aquelas formas codificadas e exóticas durante os dois dias da oficina - quatro horas diretas sem intervalo, a cada dia - embora satisfizesse parcialmente o desejo de desenvolver e aprimorar um "trabalho de corpo", deixava todos com um pequeno conjunto de interrogações na cabeça: Repetir as formas codificadas serviria apenas como aquecimento, alongamento e preparação física do atuante? Como demonstrar toda a plástica das formas codificadas sem uma poética de cena que justificasse todas aquelas sequências de movimentos exóticos? Como levar esse treinamento para atuação?

Considerando, desse modo, o treinamento com artes marciais e meditativas a partir de nosso desejo em alcançar um "trabalho de corpo", incorríamos, sem perceber, no clássico e comum equívoco de tomá-lo numa perspectiva dualista na qual o corpo é o instrumento, a ferramenta a serviço da mente, do intelecto. O corpo, portanto, considerado na perspectiva da virtuose técnica obnubilava nossa compreensão para o alcance psicofísico do treinamento. Seriam necessários anos de prática - tal como demonstrou a própria experiência de Zarrilli - para superar essa visão tão arraigada à nossa cultura ocidental. E Daquele grupo de aproximadamente trinta jovens entusiastas do "trabalho de corpo", felizmente, eu seria o que teria a oportunidade de reencontrar Cesário, o discípulo de Zarrilli, em condições mais favoráveis para minha própria iniciação no treinamento psicofísico com artes marciais e meditativas asiáticas.

\section{Conhecendo C. Sã}

No início do primeiro semestre de 2007, eu era apenas um professor substituto cumprindo o segundo ano de contrato de trabalho na Escola de Teatro e Dança da UFPA (ETDUFPA). Sem o compromisso de coordenar projeto de pesquisa, mas com o desejo de conduzir uma investigação transversal entre filosofia, música e teatro, subi a sinuosa escadaria dessa escola para ir ao encontro do coordenador do curso de licenciatura em Teatro da UFPA e solicitar sua aprovação para o projeto que pretendia conduzir naquele ano, intitulado "Filosofia e arte trágica: Nietzsche, Artaud e Morrison”. Empreendi um pouco de força para abrir a porta gigante do seu gabinete - o rangido da mesma denunciou o modelo antigo, feito de madeira bruta. Entrei e fui recepcionado por um largo sorriso do, então, coordenador Cesário Augusto que se encontrava sentado em sua mesa de trabalho. Levei um pouco de tempo para identificar que se tratava do mesmo sujeito que outrora, em dezembro de 2003, ministrara a oficina de artes marciais e meditativas. Os cabelos continuavam longos, bigode e cavanhaque estavam aparados e o porte atlético se mantinha, embora com o acréscimo de alguns quilinhos a mais, fruto de seu vício declarado por açaí. A maior diferença, no entanto, era o modo extrovertido e descontraído de falar, em contraste com a voz suave, sussurrada e introvertida dos tempos da oficina.

Ao longo da conversa descontraída sobre assuntos de trabalho, descubri outra faceta curiosa da personalidade de Cesário: sua incontida vontade por intercalar piadas ao longo das conversas, estabelecendo conexões pelos motivos mais estapafúrdios que se possa imaginar. Assim, em meio à piada do "pescosin" 
ou à do "traficante gay", falava da criação do seu grupo de pesquisa, consultando-me sobre a denominação que pretendia colocar: GITA - Grupo de Investigação do Treinamento Psicofísico do Atuante. Quando me apresentou o nome de sua pesquisa matricial, cadastrada no diretório de grupos do CNPq, fui novamente confrontado com outra peculiar faceta de sua pessoa: a escrita prolixa, atestada no título da supracitada pesquisa a seguir: "O desvelo de Procedimentos Metodológicos para Irrupções Teatrais: investigação de fatos e condições sistematizadas na preparação de performances dramatizadas alicerçadas em textos escritos por meio de estudo de casos oriundos de práticas desenvolvidas por artistas da cena". Com bom humor, Cesário dizia que esse título era um teste para verificar a aptidão do pesquisador interessado no grupo: "Se conseguir proferir o título num fôlego só e sem gaguejar, o sujeito dará conta de treinar sem perigo de ter nenhum 'piripaque' durante o trabalho!".

A conversa fluía naturalmente e quando as piadas já cediam lugar ao tom formal, que enveredaria até o convite para que eu assumisse a direção da montagem teatral em andamento pelo GITA desde o ano anterior, fomos surpreendidos por uma professora que irrompeu pela porta, aos berros, indignada: "É um absurdo! Esses alunos não respeitam ninguém! Fui destratada dentro de sala de aula e exijo que você, Cesário, como coordenador do curso, tome uma providência enérgica imediatamente". Entreolhamo-nos de soslaio e, usando aquele tom suave e sussurrado de outrora, Cesário procurou acalmá-la exercitando um pouco de seu prolixismo: "Prezada professora, fique tranquila, pois tomarei todas as providências cabíveis para que não fique impune a absurda situação ora relatada e antes vivenciada de modo vexatório por vossa prestigiada e culta pessoa que agora se encontra, com justiça, de modo sobremaneira sobressaltada e, não obstante, dignamente anelante por reparação pedagógico-administrativa."

Confesso que fiquei zonzo e já não sabia se o motivo de minha estupefação se devia ao modo descabido e descompensado da professora ou à reação pachorrenta do Cesário. A professora não se deu por convencida, aproximou-se da mesa e continuou bradando uma atitude imediata do coordenador. Cesário, que permanecia sentado, agora, apenas concordava com a cabeça, tentando dizer que no momento oportuno tomaria as providencias. As cobranças exaltadas da professora permaneceram por cerca de cinco minutos ininterruptos de esbravejamento que a mim pareciam uma eternidade, pois me encontrava bem no meio do debate. Por fim, quando tudo dava a entender que a professora seria vencida pelo cansaço, o coordenador, num ataque de fúria incontida, levanta-se, esmurra a mesa e vocifera: "Cala a boooocaaaa! Eu vou resolver o problema na hora que eu quiser e neste exato momento isso NÃ̃̃̃̃O vai acontecer por que eu tô ocupado! E saia agora da minha sala!".

O silêncio invadiu a sala. A professora se retirou com os olhos arregalados e atônitos. O coordenador se sentou delicadamente em sua cadeira e, dirigindo novamente a palavra a minha pessoa, perguntou-me com elegância e parcimônia: "Então, Edson: você aceita dirigir a montagem teatral do GITA?".

Levei um tempo para compreender que aquele acontecimento podia ser considerado uma demonstração peculiar de "tranquilidade no centro": oscilando de um extremo ao outro, Cesário deixou fluir natural e organicamente sua energia, conectando-a ao momento pre- 
sente tal como as águas do rio que se ajustam naturalmente ao seu curso. Era o modo "Cesário" de demonstrar um princípio elementar do treinamento psicofísico com artes marciais e meditativas asiáticas: estado de prontidão. Era uma pista importante de como o treinamento auxilia na atuação.

Felizmente, aceitei o convite e tive inúmeras outras experiências preciosas e inusitadas ao lado do parceiro de labuta que, carinhosamente, passou a ser chamado de C. Sã. Experiências dignas de considerá-lo, meu mestre.

GITA:

\section{o tabernáculo de C. Sã}

Embora tivesse aceitado o convite para dirigir a primeira montagem teatral do GITA, isso só viria a se concretizar quase um ano depois, em maio de 2008, quando então passei a acompanhar os ensaios da montagem que viria a se chamar "Querela-Eu" - uma livre adaptação do romance Querelle de Brest, do escritor francês Jean Genet. Àquela altura, o grupo já havia desenvolvido quase dois anos de pesquisa e possuía material suficiente para compor até duas montagens diferentes.

Antes, porém, que pudesse conferir o material produzido, C. Sã fez questão de frisar que eu seria o primeiro a ver a criação do grupo. Durante o tempo em que permaneceram no processo criativo da montagem, o GITA era um grupo anônimo na cidade e mesmo dentro da ETDUFPA havia pouquíssimo conhecimento sobre a pesquisa e treinamento praticado. A rotina do grupo contribuía para certo tom monástico: os treinos e laboratórios de criação eram somente aos sábados à tarde, sob portas fechadas e com o controle de C. Sã para trazer ou não pessoas convidadas. "É a nossa missa sagrada!", exclamava C. Sã, vez por outra, para retratar a natureza preciosa do trabalho cultivado no advento do grupo. Eu viria a compreender tamanho cuidado e respeito, quando testemunhei pela primeira vez o treinamento psicofísico praticado pelo GITA.

Era um sábado de maio de 2008. O pouco fluxo de pessoas, por volta das 16h, nas dependências da ETUDFPA, permitia reinar o silêncio e a tranquilidade. Metódico e absolutamente pontual, fui o primeiro a chegar. Em seguida chegaram Denis Bezerra, Josefa Magalhães, Juliana Tourinho e, por último, com um pouco de atraso, C. Sã portando três bastões de madeira bruta - $2 \mathrm{~m}$ de altura, aproximadamente - e uma mochila verde abarrotada de equipamentos nas costas. Do trajeto do carro até a sala de trabalho foram aproximadamente quinze minutos, com direito a algumas piadas pelo caminho, muitas risadas descontraídas e sempre um "caso" a mais para compartilhar.

O tom descontraído mudou completamente quando adentramos a sala 05 . As paredes pretas pareciam convidar ao silêncio respeitoso de um lugar sagrado. C. Sã conduziu os aproximadamente cento e dez minutos de uma prática meditativa e marcial vigorosa, com sua voz sussurrada de outrora. Posicionando-se à frente dos demais, iniciou com o hatha yoga. A tranquilidade nos permitia ouvir os ruídos da respiração voluntária de cada um, perseguindo a dinâmica puraka (inspiração), kumbhaka (retenção) e rechaka (expiração). Um olhar mais atento permitia acompanhar o movimento de descida (puraka) e subida (rechaka) do diafragma. Suryanamaskar, sukhasana, julahdhara-bandha, maha-mudra, ardha matsyendranasa, baddha konasana, vakrasana, paschimottanasana, sarvangasana, halasana, 
chakrasana, ardha-matsyasana, jathara parivrtti, ardha-shalabhasana, salabhasana, vajrasana, bakasana, shirshasana, yoga-mudra, padahasthasana, parivrtta trikonasana e vrksasana foram alguns dos asanas que foram praticados no silêncio daquela tarde.

Conduzindo tudo com o mínimo de orientação verbal - reservada para pontuar alguma coisa específica de cada asana - C. Sã prosseguiu liderando o treinamento, passando a executar os movimentos codificados do t'ai chi ch' uan, estilo wu. A respiração continuava vigorosa, mas seguia agora uma dinâmica mais fluida que parecia acompanhar milimetricamente a transferência de peso, de uma a perna à outra, durante toda a sequência de aproximadamente dez minutos ininterruptos. A sala parecia se mover sincronicamente com a leveza dos quatro praticantes à minha frente.

A qualidade da leveza e precisão dos movimentos se alterou quando iniciaram o kalarippayattu. A fluência ganhou potência e dinâmica mais ritmada na execução das posturas abstraídas de animais como o elefante, cavalo, leão e serpente. Combinações desses animais com chutes, saltos e giros remetendo a um combate imaginário dilatou ainda mais a qualidade de presença dos quatro que treinavam psicofisicamente naquela sala que agora parecia pequena demais para receber as sequências codificadas do vannakan, meyppayattu e pakkakal.

Naquele momento, compreendi todo respeito e cuidado de C. Sã com a herança que recebera de Zarrilli. E naquele momento, eu tinha o privilégio de degustar um autêntico "Zarrilli com açaí". E como "quem toma açaí fica", eu fiquei enlaçado e embevecido com o saboroso prato.
Referências

ALENCAR, Cesário A.P. de. Caderno de Pesquisa do GITA - Uma abordagem psicofísica do treinamento do atuante. Belém: UFPA / ICA/ PPGARTES, 2014.

BARBA, Eugênio; SAVARESE, Nicola. $A$ arte secreta do ator: um dicionário de Antropologia Teatral. Trad. Patrícia Furtado de Mendonça. São Paulo: É Realizações, 2012.

BENEDETTI, Robert L. (1973) "What We Need to Learn from the Asian Actor," Educational Theatre Journal 25: 463-8.

BEZERRA, Denis. Memórias cênicas: poéticas teatrais na cidade de Belém (1957-1990). Belém IAP, 2013.

ELIADE, Mircea. Yoga: imortalidade e liberdade. Trad. Teresa de Barros Veloso; transliteração do sânscrito Lia Diskin. São Paulo: Palas Athena, 1996.

FEUERSTEIN, Georg. A tradição do yoga: História, Literatura, Filosofia e Prática. Trad. Marcelo Brandão Cipolla. São Paulo: Editora Pensamento, 1998.

FLASZEN, Ludwik; POLLASTRELLI, Carla (Org.) O teatro Laboratório de Jerzy Grotowski 1959- 1969. Trad. Berenice Raulino. São Paulo: Perspectiva, 2007.

FLASZEN, Ludwik. Grotowski \& Companhia: origens e legado. Trad. Isa Etel Kopelman. $1^{\text {a }}$ Ed. São Paulo: É Realizações, 2015. 
FORTIN, Sylvie. Contribuições possíveis da etnografia e da autoetnografia para a pesquisa na prática artística. In: Revista Cena. Porto Alegre: Programa de Pós Graduação em Artes Cênicas - Instituto de Artes da UFRGS, n. 7, 2009.

Considerações metodológicas para a pesquisa em arte no meio acadêmico. In Revista de Pesquisa em Arte ABRACE, ANPAP e ANPPOM em parceria com a UFRN. Vol. 01, nº1, Jan-Jun, 2014.

GOMES, Ricardo. A tradição do ator entre Oriente e Ocidente. In Revista Sala Preta. Revista do Departamento de Artes Cênicas ECAV USP.Vol. 05, 2005.

HERMÓGENES, José. $26^{\mathrm{a}}$ ed. Autoperfeição com hatha yoga. Rio de Janeiro: Editora Record, 1971.

IBAÑES, Ana Paula. Kalarippayatt - uma via para a expressividade. Dissertação de Mestrado do Programa de Pós-Graduação em Artes da Cena do Instituto de Artes da Universidade Estadual de Campinas Federal do Pará. Belém, 2014.

KIT, Kiew Wong. O livro completo do tai chi chuan. Trad. Afonso Teixeira Filho. São Paulo: Pensamento, 1996.

LIAO, Waysun. Clássicos do t'ai chi. Trad. Marcelo Brandão Miranda. São Paulo: Pensamento, 1990.

LIMA, Wlad. O teatro ao alcance do tato. Belém. Programa de Pós-Graduação em Artes/ ICA/UFPA, 2014.
MIRANDA, Caio. Hatha, o abc do yoga. Rio de Janeiro: Ediouro, 1979.

NICHOLS, Richard. Asian martial arts as a "way" for actors. In: ZARRILLI, Phillip (Ed.). Asian martial arts in actor training. Wisconsin: University of Wisconsin-Madison, 1993, p.1930.

ZARRILLI, Phillip(ed.). Asian martial arts in actor training. Wisconsin: University of Wisconsin-Madison, 1993, 124p.

.(Ed.). Acting (Re) considered: Theories and Pratices guide. London: Routledge, 1995, 378p. When the body becomes all eyes: paradigms, discourses and practices of power in kalarippayattu, a South Indian martial art. New Deli: Oxford University Press, 2000, 310p.

Recebido: 31/08/2016 Aprovado: 16/08/2016 